has kindly examined a pair and compared descriptions and regards it as new.

I am informed by Mr. Cameron of the Botanic Garden that these insects were troublesome in the greenhouse for five or six years, eating the tender green leaves of many kinds of plants and seeming to be particularly fond of ferns; also, that they were believed to have come originally from Jamaica. Their extermination is believed to have been effected at least in part through the introduction into the greenhouse of a number of small frogs.

\title{
ANTS CARRIED IN A FLOATING LOG FROM THE BRA- ZILIAN MAINLAND TO SAN SEBASTIAN ISLAND.
}

\author{
By William Morton Wheeler, \\ Bussey Institution, Harvard University.
}

Dr. Hermann von Ihering, the well-known writer on zoögeography and till recently the director of the Museu Paulista of San Paulo, Brazil, has sent me for identification some ants which were taken under the peculiar circumstances described in the following paragraph quoted from his letter:

"I find that the 'raft-theory' of dispersal has generalized some exact observations in an extraordinary manner. Here in South America we have wonderful opportunities to observe the 'swimming islands' in the great rivers, although the upper and lower courses of these streams have to a considerable extent their own peculiar faunas. My experiments with wood, bamboo, etc., containing ant-colonies, have demonstrated that the latter are decidedly resistant to submersion provided their nest-entrances are closed. Till the current year, one of our naturalists, Mr. Gaste, was, however, unsuccessful in his various excursions in finding living insects in wood that had drifted from our coast. One morning, while he was on the island of San Sebastian, he found a tree trunk that had floated to the shore during the night and was filled with a living ant-colony belonging to a species of Pheidole unknown to me. San Sebastian is situated some kilometers off the coast of the main land. Of course, we cannot say how long this 
log had been floating in the water before it reached the island. Please examine the ants," etc.

The portion of the ant-colony received from Dr. von Ihering consists of a single soldier, five workers and three young, winged females, representing a new species of Pheidole of which I subjoin a description.

\section{Pheidole peregrina sp. nov.}

Soldier: Length, $3.2 \mathrm{~mm}$. Allied to $P h$. pubiventris Mayr, rufipilis Forel, and angusta Forel, especially to the last. Head small, subrectangular, a little longer than broad, as broad in front as behind, with rather straight sides and feebly excised posterior margin. Eyes moderately large and convex, in front of the middle of the sides of the head. Mandibles rather large, indistinctly denticulate in the middle, with two large apical and two small basal teeth. Clypeus with a short carina behind, concave in front, with rather deeply notched anterior border. Frontal area distinct, triangular, not deeply impressed, with median carinula. Frontal carinæ short. Antennal scapes rather stout but not flattened, curved at their bases, their tips reaching a little more than half the distance between the eyes and the posterior corners of the head. Joints $2-7$ of the funiculus scarcely longer than broad, club a little longer than the remainder of the funiculus, its two basal joints subequal, together as long as the terminal joint. Thorax shaped much as in pubiventris, but the pronotum without prominent humeral tubercles and the epinotal spines reduced to small, erect teeth which are not longer than broad at their bases. Petiolar node compressed anteroposteriorly, with indistinctly emarginate, transverse superior border. Postpetiole less than twice as broad as the petiole, with rounded sides and dorsal surface. Gaster elongate elliptical, with distinctly truncated anterior border. Legs moderately long.

Smooth and shining: mandibles coarsely and sparsely punctate; cheeks and front rather loosely longitudinally rugose; remainder of head with sparse, fine, piligerous punctures. Mesonotum, epinotum and sides of petiole opaque, very finely and obscurely punctate-rugulose.

Hairs short, abundant, pale yellow, reclinate, covering the whole body and the appendages, longest on the gaster, which, however, has no appressed hairs. Pubescence absent. 
Brownish yellow, legs a little paler, clypeus and posterior portion of gaster somewhat darker; antennal clubs blackish.

Worker: Length, $2 \mathrm{~mm}$. Head distinctly longer than broad, narrower behind than in front, without posterior corners but with distinct, reflected occipital margin. Eyes in front of the middle of the sides. Mandibles finely denticulate, with two larger apical teeth. Anterior clypeal border straight, transverse and entire in the middle. Antennal scapes extending about one-fourth their length beyond the occipital border of the head. Thorax, petiole, postpetiole and gaster much as in the soldier, but epinotal teeth more slender and pointed and a little longer than broad at their bases.

Sculpture and pilosity as in the soldier but the hairs are somewhat more erect.

Brownish yellow, mandibles paler, head, clypeus and terminal antennal joint castaneous. In some specimens the middle portions of the femora and tibiæ are very feebly infuscated.

Female: Length, 5-5.5 mm. Head distinctly broader than long, a little broader behind than in front, with straight sides and feebly excavated posterior border. Mandibles finely denticulate, with two large apical teeth. Clypeus as in the soldier. Antennal scapes reaching to the posterior corners of the head. Thorax of the usual shape, with strongly flattened mesonotum; epinotum with acute teeth as long as broad at their bases. Petiolar node rather low, its upper border sharp and entire.

Sculpture, pilosity and color much as in the soldier, but the head indistinctly rugulose and coarsely punctate over its whole dorsal surface, the mesonotum more densely punctate and behind on the middle finely and densely striolate, the postpetiole opaque and finely punctate and the gaster brown, except at the base. Ocellar region black. Wings yellowish hyaline, with pale yellow veins and pterostigma.

This species differs from pubiventris, rufipilis and angusta in its smaller size, in pilosity and in the head of the soldier being even smaller than in angusta. The hairs of peregrina are more reclinate, more abundant and shorter than in any of these species, the epinotal spines are less developed, the pronotum is smooth and rounded, without tubercular humeri in the soldier and the head 
of the worker is longer and has a reflected occipital margin which is lacking in pubiventris and angusta.

The observations of Mr. Gaste and Dr. von Ihering throw light on one of the methods of ant dispersal. Of course, the establishment of a species of ant on an island does not require the conveyance of a whole colony as in this instance, since a single fecundated female enclosed in a vegetable cavity might, if transported in a similar manner, suffice for the establishment of a species.

\section{ON THE TYMPANUM OF CERTAIN LEPIDOPTERA.}

\section{By William T. M. Forbes, Ithaca, N. Y.}

At the base of the abdomen in many Lepidoptera there is a curious and complex organ, which has been referred to but rarely in the literature, and which is known, in the Geometridæ, at least, as the tympanum. So far as I have discovered, its function is unknown, but its location and general structure justify the guess that it is the resonator for an auditory organ, corresponding to the well-known one in the Hemiptera. It should prove an interesting problem for the histologist and physiologist. The present article will not consider its function, but will outline its structure in the principal families of Macrolepidoptera, and offer a couple of suggestions as to their relationship.

A brief examination shows that there are several analogous, but not homologous organs of this type in the various families, indicating parallel lines of descent from a form that presumably had neither, but may have possessed a wholly internal sense-organ,-which served as a stimulus to their forma-

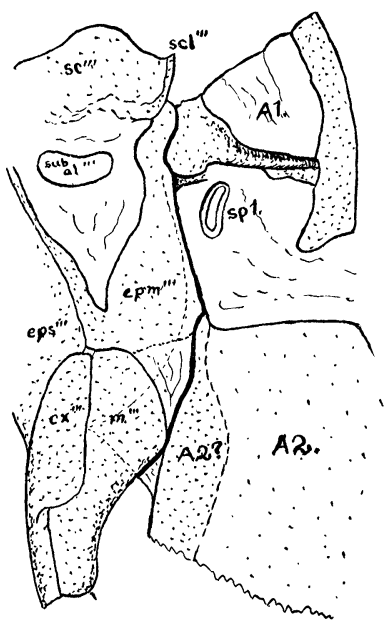

Fig. 1. Side view of metathorax and base of abdomen of Apatelodes torrefacta (Eupterotidæ), showing primitive macrolepidopterous arrangement of sclerities. 

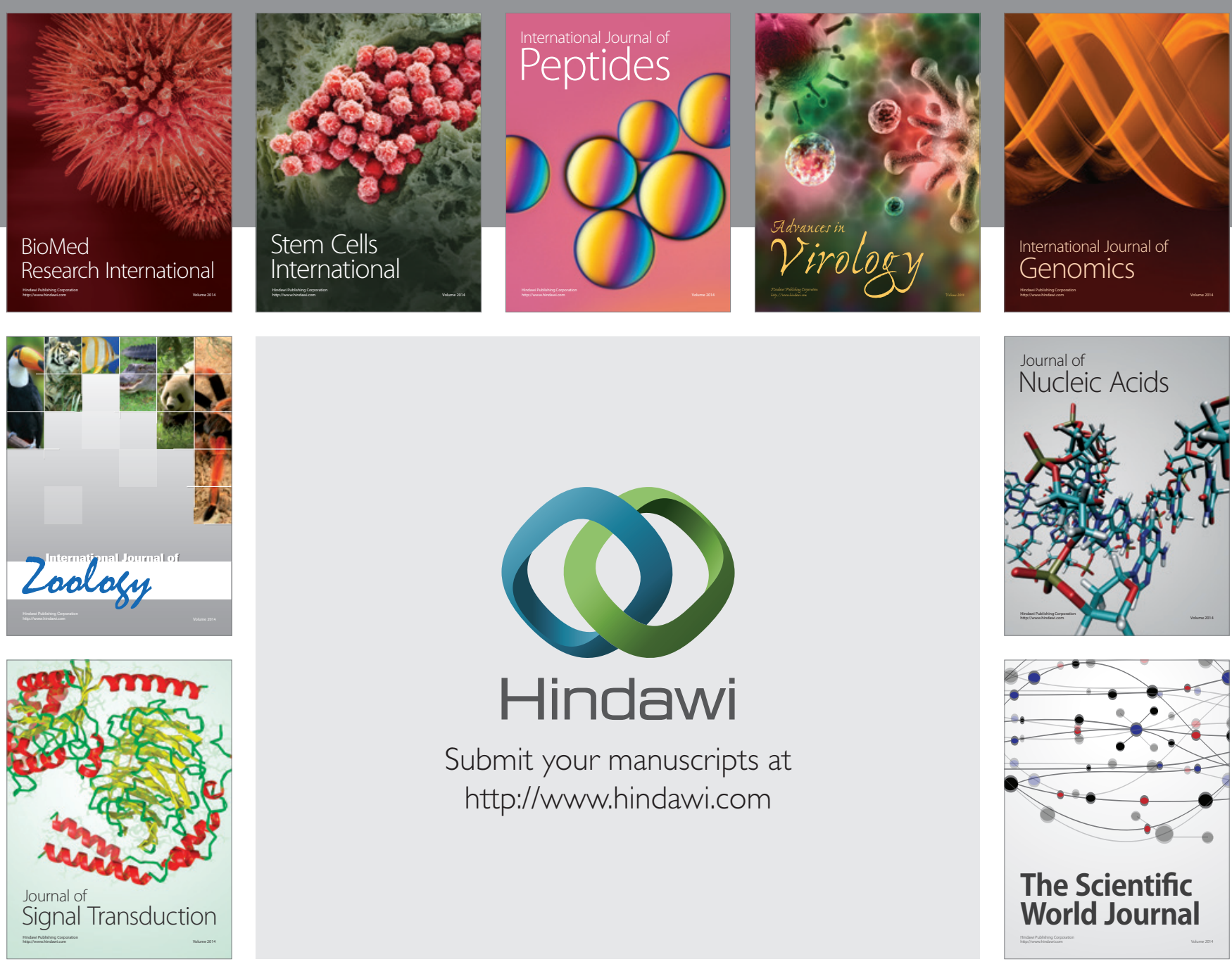

Submit your manuscripts at

http://www.hindawi.com
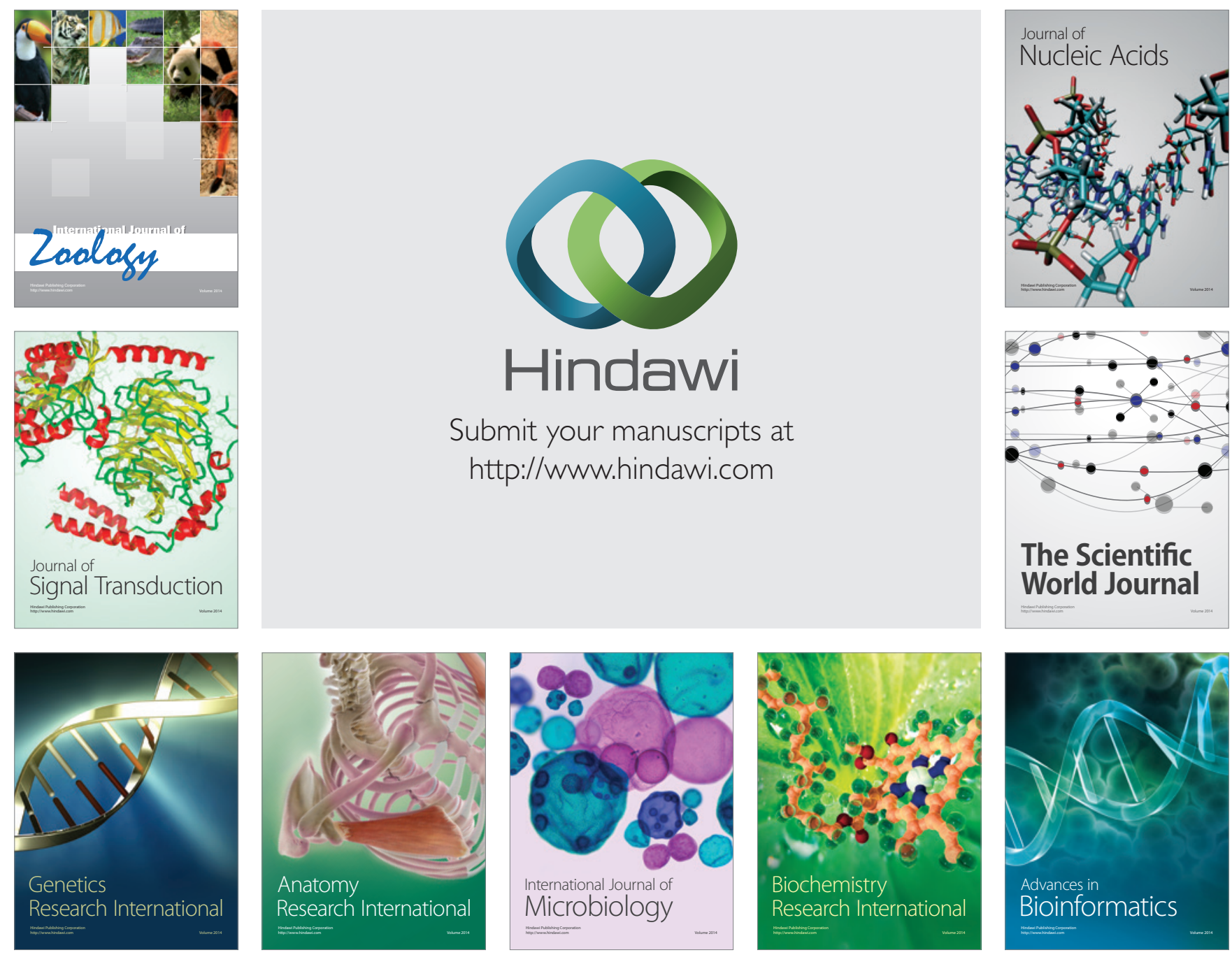

The Scientific World Journal
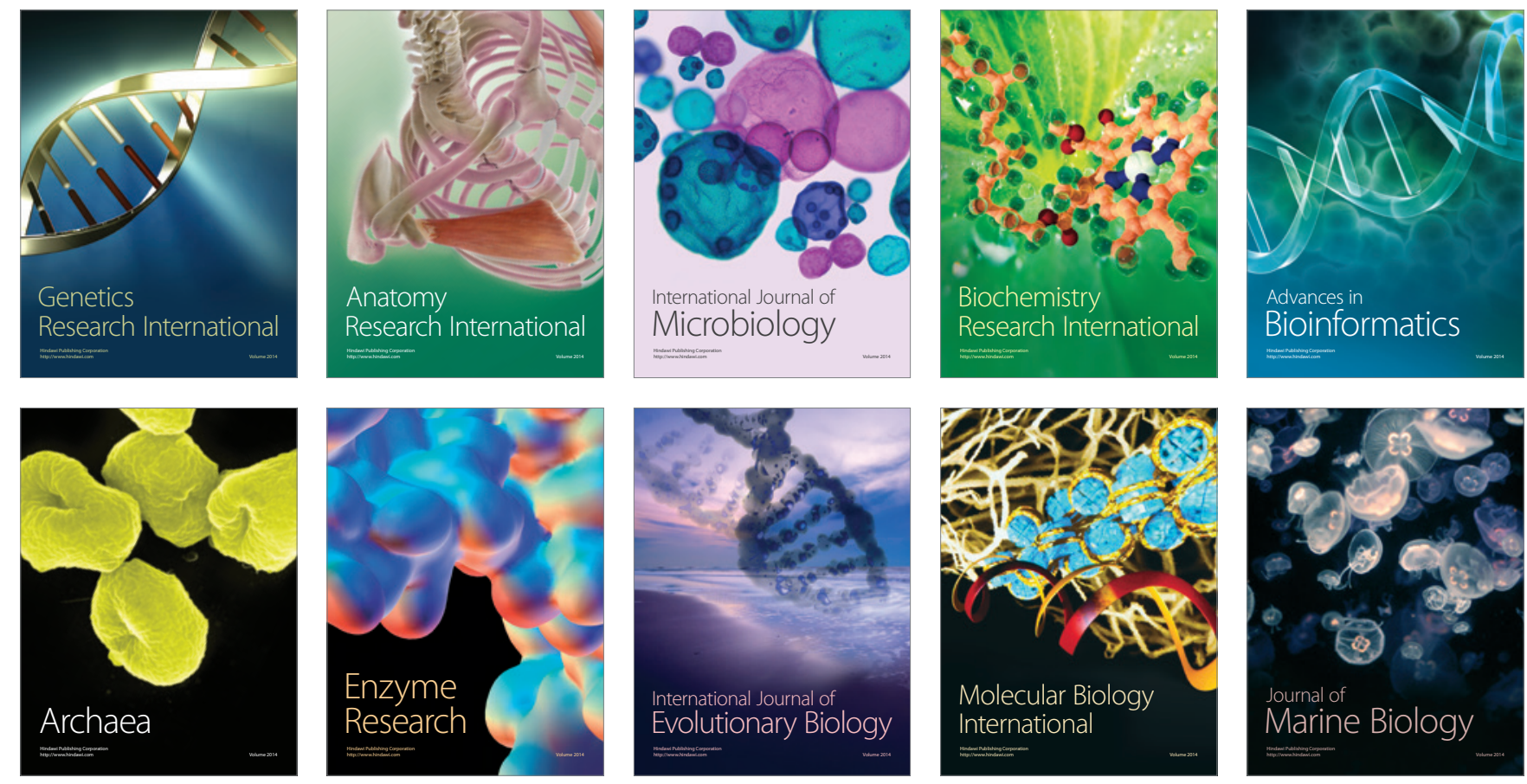